\title{
VINTRODUÇÃO 5 ANOS DE PLANO NACIONAL DE EDUCAÇÃO: O QUE APRENDEMOS?
}

\author{
Gustavo Henrique Moraes ${ }^{\mathrm{I}}$
}

\author{
Ana Elizabeth M. Albuquerque ${ }^{\mathrm{II}}$ \\ Robson dos Santos ${ }^{\mathrm{III}}$
}

http://dx.doi.org/10.24109/9786581041076.ceppe.v2intro

No último dia 25 de junho, comemorou-se os cinco anos de publicação do Plano Nacional de Educação (PNE). A data marcou a passagem de metade da duração de um Plano cuidadosamente concebido para transformar a educação nacional em um prazo de dez anos. Avaliar o sucesso ou o fracasso de tal empreitada, ao final do período de vigência do PNE, requer o seu monitoramento contínuo, de modo que seja possível informar as políticas públicas que podem garantir o êxito das suas metas ou reorientar as ações em curso.

Desde a publicação da Lei $\mathrm{n}^{0}$ 13.005, de 25 de junho de 2014, cabe ao Inep a responsabilidade de elaborar e publicar os estudos para aferir a evolução no cumprimento das metas estabelecidas no PNE. Em âmbito interno, essa responsabilidade fica a cargo da Diretoria de Estudos Educacionais (Dired), que concretiza a tarefa por meio da publicação de materiais como o Plano Nacional de Educação - Linha de Base; os Relatórios de Monitoramento do PNE, da série PNE em Movimento; e os Cadernos de Estudos e Políticas Educacionais, documentos que visam conferir ao monitoramento e à avaliação do PNE a legitimidadeea objetividadecientífica que o desenvolvimento da educação brasileira requer.

A utilização dessas produções por diversos setores da sociedade é sinal de que o conjunto de trabalhos tem sido fundamental para acompanhar a evolução dos sistemas educacionais, permitindoum olhar mais aprofundado sobrea realidadebrasileira. Indoalém do caráter informativo, os resultados expressos nas pesquisas feitas pelo Inep dão suporte à gestão e à consecução de política públicas, balizando decisivamente os rumos da educação.

\footnotetext{
Doutor em Educação pela Universidade de Brasília (UnB) e mestre em Educação Científica e Tecnológica pela Universidade Federal de Santa Catarina (UFSC) e engenheiro em Eletrônica e Telecomunicações pela Universidade Tecnológica Federal do Paraná (UTFPR). Privilegia as abordagens que buscam conciliar as esferas qualitativas e quantitativas da pesquisa, respaldadas por abordagens históricas e estatísticas. Pesquisador do Inep ocupando o cargo de coordenador geral de Instrumentos e Medidas Educacionais da Diretoria de Estudos Educacionais (Dired) do Inep, sendo responsável pelos estudos de monitoramento do Plano Nacional de Educação (PNE).

II Doutora em Educação e mestre em Gestão da Educação pela Universidade de Brasília (UnB). Pesquisadora do Instituto Nacional de Estudos e Pesquisas Educacionais Anísio Teixeira (Inep). Professora de Educação Profissional e Tecnológica. Atua principalmente nos seguintes campos: políticas públicas e gestão da educação; educação profissional e tecnológica.

III Doutor e mestre em Sociologia pela Universidade Estadual de Campinas (Unicamp) e em Política Social pela Universidade de Brasília (UnB). Possui especialização em estatística aplicada. Tem experiência como sociólogo em órgãos da administração pública federal como docente de sociologia no ensino médio e na educação superior. Atualmente, trabalha como pesquisador-tecnologista em Informações e Avaliações Educacionais no Instituto Nacional de Estudos e Pesquisas Educacionais Anísio Teixeira (Inep). Áreas de interesse e atuação atuais: sociologia da educação, educação de populações do campo, educação de jovens e adultos, indicadores educacionais e métodos quantitativos em ciências sociais.
} 
Para nós, pesquisadores do Inep, a tarefa que se iniciou como o cumprimento de uma obrigação legal transformou-se em uma responsabilidade que mobiliza tanto competências técnicas quanto um genuíno compromisso com o desenvolvimento da educação nacional. Reconhecendo a natureza estratégica desse trabalho, não seria interessante conhecer o que os autores dessas produções técnico-científicas têm aprendido no processo de elaborar, implementar e avaliar os resultados dos indicadores do PNE?

Dividir tal experiência e o aprendizado que resultou dela representa o objetivo deste texto de abertura do volume 2 do Caderno de Estudos e Pesquisas Educacionais do Inep.

\section{A CONSTRUÇÃO DA ESTRUTURA METODOLÓGICA}

Entre os avanços obtidos no trabalho de constituição do monitoramento do PNE, deve-se destacar a construção de uma estrutura metodológica capaz de acompanhar a evolução de suas metas. É importante alertar que a tarefa antecedeu o próprio Plano, pois antes mesmo de sua aprovação, o Inep se debruçou sobre o projeto de lei com a finalidade de encontrar os melhores caminhos metodológicos para o seu monitoramento. A Linha de Base, documento que faz uma contextualização educacional de cada uma das metas no início da vigência do Plano, constituiu esse esforço inicial de construção, sistematização e aperfeiçoamento dos métodos que seriam empregados no acompanhamento do PNE.

O ponto mais destacado dessa construção metodológica foi, certamente, a constituição de um conjunto de indicadores que permitem um retrato contínuo de cada uma das metas do Plano. Destaque-se que esses indicadores decorrem da própria estrutura da Lei $\mathrm{n}^{\mathrm{0}}$ 13.005/2014, disposta em torno de metas e objetivos, em geral, quantificáveis, que tornam as responsabilidades públicas mais inteligíveis, permitindo o desenvolvimento de modelos de monitoramento e avaliação mais consistentes das políticas públicas. Frise-se que a delimitação de objetivos quantitativos para as metas do Plano não se confunde com a redução de seus significados, ou a simplificação das aspirações educacionais traçadas para o País a patamares mais modestos. Na interpretação derivada do trabalho de monitoramento, entendeu-se que o texto legal optou por firmar as responsabilidades públicas em horizontes quantificáveis que podem ser objetivamente vislumbrados e reivindicados.

Ao contrário do que se possa ingenuamente imaginar, o trabalho de construção do monitoramento e avaliação do PNE não está inscrito em soluções automáticas, em sistemas de informática que, previamente programados, fornecem relatórios atualizados das realidades que desejamos investigar. A tarefa de monitoramento requer uma complexa organização teórica, metodológica e tecnológica, especialmente concebida para esse fim. 
A investigação exige, antes de tudo, um preparo teórico que possibilite ao pesquisador a compreensão do processo educacional que será analisado. Por se tratar de um objeto complexo, multidimensional, a Educação não admite investigações circunscritas a campos disciplinares isolados, mas requer um olhar interdisciplinar, no qual as compreensões da História, da Pedagogia, da Estatística, da Sociologia, da Psicologia, da Economia, da Demografia e de tantas outras especialidades são imprescindíveis. No estudo da Educação, a interdisciplinaridade não é uma escolha didática, mas um pressuposto epistemológico.

A interdisciplinaridade, contudo, não se faz só de letras, mas também de números. Assim, não podemos aderir ao discurso que apregoa uma investigação estritamente qualitativa da Educação, rejeitando as contribuições que a Matemática nos oferece. É preciso recorrer às ferramentas estatísticas e a diferentes estratégias metodológicas para a busca e escrutínio de evidências que nos auxiliem na compreensão da realidade investigada. É partindo dessa compreensão epistemológica que se edifica o rigor metodológico construído para o monitoramento do PNE: a pesquisa, de natureza interdisciplinar, deve se pautar na busca de evidências científicas e, sempre que possível, em evidências estatísticas.

Essa não é uma tarefa fácil. Deve-se, de imediato, rejeitar a compreensão de que o Estado reúne todas as informações necessárias para a rápida verificação da realidade. Isso não é verdade. As possibilidades de investigação estão sempre limitadas ao conjunto de pesquisas estruturadas pelo Estado brasileiro, com suas respectivas bases de dados, assim como às distintas temporalidades e finalidades que caracterizam cada uma delas.

Algumas das pesquisas utilizadas para o monitoramento e a avaliação do PNE são produzidas pelo próprio Inep, em minuciosos processos de coleta de dados, validação de informações e disseminação de resultados estatísticos; é o caso das bases oriundas do Censo Escolar da Educação Básica, do Censo da Educação Superior, do Sistema de Avaliação da Educação Básica (Saeb) e do Exame Nacional do Ensino Médio (Enem). Outras são produzidas por distintas autarquias do Ministério da Educação, como as bases referentes à pós-graduação, produzidas pela Coordenação de Aperfeiçoamento de Pessoal de Ensino Superior (Capes), e as que trazem os dados financeiros da Educação, produzidas pelo Fundo Nacional de Desenvolvimento da Educação (FNDE). Por fim, há aquelas que têm origens em outros Ministérios, tais como as bases de dados do Censo Populacional, da Pesquisa Nacional por Amostra de Domicílios Contínua (PnadC), da Pesquisa de Informações Básicas Estaduais (Estadic), da Pesquisa de Informações Básicas Municipais (Munic) - produzidas pelo Instituto Brasileiro de Geografia e Estatística (IBGE) - e da Relação Anual de Informações Sociais (Rais), do Ministério da Economia.

A primeira tarefa, nada trivial, é reunir todas as bases necessárias à investigação - um processo que envolve a negociação técnica e política entre os órgãos geradores, critério fundamental para a garantia do bom uso dessas informações. De posse desse 
conjunto de bases de dados, é preciso prepará-las para a investigação. Isso requer que o pesquisador reúna as competências necessárias para manipulá-las. Este preparo demanda a habilidade de operar as plataformas e pacotes de tratamento estatístico, dominando suas diversas linguagens de programação, sem as quais se torna impraticável acessar e manipular as gigantescas bases de dados que se constituem em fontes primárias para a produção do conhecimento educacional.

O domínio dessas habilidades técnicas, contudo, não é garantia de que um pesquisador conseguirá navegar por qualquer base de dados sem empregar grandes esforços à compreensão de suas particularidades. Isso porque cada uma delas é única, tendo sua própria estrutura. O pesquisador que se aventura pela exploração de um conjunto de dados deve desvendar a sua complexa estrutura de verbetes, a semântica que lhe é própria, o rol de categorias, de marcadores, de dicionários de dados, que procuram indicar a lógica de sua construção, bem como entender as sutis mudanças que nelas ocorrem ao longo do tempo. Cada base de dados é como uma cidade, com sua emaranhada trama viária, cheia de caminhos, encontros, cruzamentos, atalhos e, também, ruas sem saída. Não basta ser um motorista habilidoso para deslocar-se de um ponto a outro, é preciso conhecer suas avenidas, suas regras de trânsito, a sinalização que a orienta, seus trechos de lentidão, seus bairros, seu plano de uso e ocupação.

Conseguir se mover pelo trânsito de uma dessas cidades já é tarefa custosa e a dificuldade aumenta quando precisamos conectá-las. Na maior parte dos casos, não há caminhos de ligação entre elas, o que limita a expansão de nossos conhecimentos às dimensões mais restritas da realidade. Há casos, porém, em que uma chave primária comum, tal como números de CPFs, viabiliza uma estrada de comunicação entre esses mundos. Assim, poderemos investigar, por exemplo, se os egressos dos cursos de licenciatura estão, efetivamente, tornando-se professores nos sistemas de ensino. Essas vias de conexão, no entanto, têm circulação controlada, sendo reguladas pelas disposições voltadas à segurança dos dados pessoais e protegidos. De fato, conseguir as licenças para trafegar nessas vias é o desejo de muitos pesquisadores brasileiros.

Somente agora, equipados de suas constituições filosóficas e limitados pelas vias de informação que se podem alcançar, é que os pesquisadores do Inep podem propor o conjunto de indicadores que visam traduzir em números a evolução das metas do PNE e produzir estudos que permitam entender quais os impeditivos que restringem a consecução dos objetivos traçados. A robustez dos dados, porém, não os converte em um espelho da realidade. Antes disso, as construções estatísticas refletem pressuposições teóricas e são reféns das limitações tecnológicas que utilizamos para a investigação de um objeto educacional.

Por isso, é sempre importante reafirmar que os indicadores de acompanhamento das metas do PNE constituem sínteses de realidades complexas. É nesse sentido que os estudos têm a finalidade de aprofundar as análises e iluminar as sinuosidades que caracterizam cada uma das metas do Plano. 


\section{A ELABORAÇÃO DOS ESTUDOS}

O uso cada vez mais frequente de evidências para o acompanhamento de políticas educacionais, como dito, constitui um ganho ao desenvolvimento de ações que tenham consequências efetivamente positivas nos sistemas educacionais. Esse uso é, obviamente, ancorado na descrição quantitativa possibilitada pelos indicadores, mas reivindica um esforço de cunho analítico que contextualize os dados, que os associem com as políticas que devem impactá-los, dados os contextos em que eles ocorrem. Assim, onde tínhamos números surge a necessidade das letras.

Escrever não é simplesmente transpor ao papel (ou à tela) as ideias que já trazemos prontas em nossas cabeças. Ao contrário, é interrogar as próprias ideias, é formular a questão correta aos dados, a fim de produzir uma concepção organizada, um discurso teórico coerente com a realidade observada por meio dos números. É desse diálogo constante entre teoria e evidência que se constrói a pesquisa e, de certa forma, o pesquisador em educação - transformado pelas reflexões constituintes do seu próprio trabalho.

O trabalho da escrita, ainda que exija certo isolamento para constituir-se, não deve ser solitário, demandando a necessária avaliação e validação de pares científicos. No Inep isso ocorre, primeiramente, quando os resultados iniciais da pesquisa são apresentados (na estrutura de seminários internos) ao conjunto de pesquisadores da Dired, que, dialogando criticamente com o pesquisador responsável pelo monitoramento da meta, buscará refinar o conhecimento promovido.

Depois, já no nível da produção escrita, os textos são submetidos a revisores internos, buscando a sua qualificação. Segue-se a etapa de revisão externa, levada a efeito por um parceiro institucional, habitualmente algum cientista que integre a Comissão Assessora de Especialistas do Inep. Por fim, as produções são submetidas a um rigoroso processo de revisão textual, normalização técnico-científica e diagramação, garantido pelo trabalho da Coordenação de Editoração e Publicação.

Vale destacar que cada material de divulgação requisita uma estratégia diferente de elaboração e comunicação. Desse modo, enquanto os Relatórios de Monitoramento do PNE oferecem um registro, em série histórica, das tendências dos indicadores e da evolução das metas, os textos inclusos nos Cadernos de Estudos e Pesquisas em Políticas Educacionais visam oferecer uma explicação, isto é, trazer análises que ajudem a entender que fatores, processos, contextos e condições características de cada nível e etapa da educação brasileira induzem ou restringem o alcance dos objetivos traçados pelo Plano. 


\section{O APRENDIZADO SOBRE AS METAS}

As considerações feitas até aqui refletem os aprendizados institucionais e metodológicos para a produção do monitoramento do PNE. Todavia, essas ponderações seriam incompletas sem uma apresentação de questões relativas ao PNE enquanto política pública, acerca de seus avanços e dificuldades e dos caminhos que podem ser considerados nos cinco anos que restam para sua conclusão.

Como dito, o monitoramento feito até aqui ensinou que é fundamental a definição de objetivos quantificáveis, um avanço do atual PNE, mas que isso também deve ser articulado aos sistemas de coleta e divulgação de dados estatísticos, de modo que se estabeleçam objetivos que contem com dados que autorizem a compreensão dos avanços e informem sobre as barreiras existentes. Nesse sentido, cabe apontar algumas questões que podem limitar o eficiente monitoramento do PNE:

\section{I) AUSENNCIA OU INSUFICIÊNCIA DE BASES DE DADOS PARA O MONITORAMENTO DAS METAS}

Há casos em que as bases de dados disponíveis não são suficientes para realizar um monitoramento eficaz das metas do PNE. A Meta 4 da Lei $n^{0} 13.005 / 2014$, por exemplo, define como finalidade

[...] universalizar, para a população de 4 (quatro) a 17 (dezessete) anos com deficiência, transtornos globais do desenvolvimento e altas habilidades ou superdotação, o acesso à educação básica e ao atendimento educacional especializado, preferencialmente na rede regular de ensino [...]

A meta possui dois objetivos: universalizar o acesso escolar e garantir que ele seja feito com inclusão. Este último pode ser monitorado anualmente com base no Censo Escolar do Inep, inclusive em nível municipal. Já a universalização do acesso para o referido público não conta com dados periódicos, pois o levantamento mais atual disponível acerca do conjunto da população, inclusive dos que estão fora da escola, é o que consta no Censo Demográfico de 2010 - anterior à aprovação do PNE - sendo o próximo o que emergirá do Censo de 2020, o qual disponibilizará dados, possivelmente, apenas em 2021.

Desse modo, um importante objetivo da Meta 4 não pode ser monitorado com uma periodicidade que seja adequada à tomada de decisão, isso mesmo com a determinação contida no parágrafo único do artigo $4^{\circ}$ da Lei $n^{0} 13.005 / 2014$, de que “o poder público buscará ampliar o escopo das pesquisas com fins estatísticos de forma a incluir informação detalhada sobre o perfil das populações de 4 (quatro) a 17 (dezessete) anos com deficiência”. Tal situação explicitou a necessidade de que os planejamentos educacionais tracem objetivos tendo em conta a disponibilidade de meios para o seu acompanhamento. 


\section{II) INSUFICIÊNCIA DOS DIAGNÓSTICOS PRÉVIOS PARA A DEFINIÇÃO DAS METAS}

O esforço para a constituição de indicadores para o monitoramento dos objetivos das metas deparou-se, em alguns casos, com a ausência de diagnósticos prévios mais detalhados acerca da situação que era existente nos vários níveis e etapas educacionais. Em certa medida, isso pode ter contribuído na definição de objetivos que, por vezes, foram subestimados, e, em outras, superestimados, como indica a série histórica monitorada, inclusive com dados dos anos que precederam a aprovação do Plano.

É o caso da Meta 13. O PNE estipulava que 35\% do corpo docente em efetivo exercício no conjunto do sistema de educação superior deveria possuir doutorado. Em 2014, ano de aprovação do PNE, o valor já era de 35,5\%, estando a meta cumprida. De outro lado, a Meta 10 definiu que, até 2024, no mínimo 25\% das matrículas de educação de jovens e adultos sejam integradas à educação profissional. Em 2013, ano que antecedeu a aprovação do PNE, o valor era de apenas 2,8\%, e, em 2017, de $1,5 \%$, o que exigiria um crescimento muito acelerado, que não foi constatado na série histórica precedente.

A mesma situação pode ser encontrada na Meta 11 da Lei $n^{0} 13.005 / 2014$, que estabeleceu como objetivo "triplicar as matrículas da educação profissional técnica de nível médio, assegurando a qualidade da oferta e pelo menos 50\% (cinquenta por cento) da expansão no segmento público”. Em 2013, o número de matrículas era de 1.602.946, o que significa que, até 2024, será necessário atingir mais de 4 milhões de matrículas para garantir o triplo. No ano de 2017, o número de matrículas era de 1.791.806, ainda distante da meta.

Desse modo, o monitoramento e os estudos conduzidos têm apontado que a ausência de diagnósticos prévios e evidências mais consistentes para o estabelecimento de metas podem gerar objetivos "inalcançáveis", desestimulando o delineamento de políticas e o engajamento dos atores, ou o estabelecimento de objetivos que simplesmente já realizados ou quase atingidos desde o princípio, não demandando esforços e/ou políticas.

\section{III) EXISTÊNCIA DE METAS E ESTRATÉGIAS SEM OBJETIVOS FACILMENTE QUANTIFICÁVEIS}

Como foi dito, diversas metas são bem definidas no que se refere aos objetivos traçados, mas, em alguns casos, isso é menos explícito, como nas Metas 18 e 19, que tratam, respectivamente, da existência de planos de carreira para os profissionais da educação e da efetivação da gestão democrática escolar. Esse fenômeno acarreta dificuldades ao monitoramento, considerando-se a ausência de medidas disponíveis ou mesmo de bases de dados regulares. 
É importante lembrar que o PNE é composto também por estratégias, entendidas, no trabalho que vem sendo realizado, como meios pelos quais as metas devem ser atingidas. Por vezes, as estratégias foram definidas de forma quantitativa e objetiva confundindo-se com as metas em si. Como exemplo temos a Estratégia 1.2 da Lei no 13.005/2014:

garantir que, ao final da vigência deste PNE, seja inferior a 10\% (dez por cento) a diferença entre as taxas de frequência à educação infantil das crianças de até 3 (três) anos oriundas do quinto de renda familiar per capita mais elevado e as do quinto de renda familiar per capita mais baixo.

Em outros casos, as estratégias se constituem como princípios gerais e podem formar diretrizes para as políticas públicas, mas sem objetivos quantificáveis - o que impede um monitoramento mais detalhado (como exemplo, a Estratégia 3.4 da Lei $\mathrm{n}^{\mathrm{o}}$ 13.005/2014: "garantir a fruição de bens e espaços culturais, de forma regular, bem como a ampliação da prática desportiva, integrada ao currículo escolar”).

\section{IV) DIFICULDADE EM MONITORAR A EVOLUÇÃO MUNICIPAL E ESTADUAL DAS METAS}

Outra constatação trazida pelo monitoramento é a necessidade de considerar todos os entes federados. No que se refere aos municípios, o cenário descrito para a Meta 4 pode ser espraiado para todas as metas que tratam de universalização do acesso à educação básica (Metas 1, 2, 3, 4). Como o único mecanismo de informações robustas sobre o conjunto da população, inclusive da que está fora da escola, provém do Censo Demográfico do IBGE, os municípios têm encontrado dificuldades para obter dados sobre a população existente, o que afeta o monitoramento de suas metas e também o dimensionamento das políticas de acesso à creche, à pré-escola, ao ensino fundamental, entre outros.

Assim, os dados de monitoramento do PNE publicados pelo Inep, no caso da universalização, referem-se apenas ao nível de agregação dos estados. Somente com a divulgação dos dados do Censo Demográfico de 2020 será possível um diagnóstico mais acurado da situação nos municípios, tendo em vista as metas que eles definiram em seus Planos. Esse fato precisa ser levado em conta ao longo do atual Plano, mas também nos planejamentos subsequentes.

Ainda nesse campo, é importante recordar que as metas do PNE não são necessariamente as mesmas dos Planos Estaduais e Municipais. Os entes federados possuem autonomia para definir seus objetivos, tendo o PNE como uma diretriz, mas, em muitos casos, não é possível simplesmente replicar todas as metas do PNE para os Planos Estaduais ou Municipais. Quanto a isso, o monitoramento permitiu visualizar que alguns entes replicaram metas do PNE, assumindo objetivos que, por vezes, fogem ao seu escopo de ação. Essa situação confirma a necessidade de que as 
ações traçadas levem em conta a efetiva realidade local e os desafios que são próprios de cada contexto, tendo em vista os recursos disponíveis.

Sobre isso, é preciso ter em conta que o monitoramento do PNE não se confunde com o monitoramento dos planos estaduais ou municipais. É importante que planejamentos educacionais posteriores conduzam a uma articulação maior das ações e responsabilidades, de modo a tornar mais delimitado o que deve ser atribuído, bem como monitorado em cada nível.

\section{V) RISCOS DE INCOMPREENSÃO DE REALIDADES QUANDO OBSERVADAS DE MANEIRA AGREGADA}

O monitoramento das metas do PNE permitiu também compreender que, em diversos casos, é necessário que se proceda à desagregação dos dados, de modo que se compreenda melhor as desigualdades que acompanham a concretização de uma meta. Como exemplo, o acesso ao ensino fundamental encontra-se em patamares próximos à universalização, como demanda a Meta 2. Todavia, quando se procedeu à análise do percentual que concluiu o ensino fundamental na idade adequada, os dados apontavam que, em 2017, 78\% dos residentes nas áreas urbanas com 16 anos de idade possuíam o fundamental completo; já no campo, o valor era de 65,3\%. Uma diferença de mais de 12 pontos percentuais. Nesse caso, a Meta 2 define como o objetivo que, até 2024 , 95\% da população conclua o ensino fundamental na idade recomendada.

Este exemplo ilustra um dos aprendizados importantes trazidos pelo trabalho. O cenário educacional brasileiro é marcado por diferenças e desigualdades. O alcance de um objetivo visto de modo agregado em nível nacional, por vezes, oculta a dispersão e a assimetria dos cenários. O nível socioeconômico, as desigualdades regionais, étnico-raciais, entre outras, precisam ser levadas em conta para uma compreensão mais acurada acerca dos significados contidos no resultado de um número isolado.

\section{VI) POUCAS DEFINIÇÕES QUANTO A OBJETIVOS INTERMEDIÁRIOS}

Algumas metas contam com objetivos intermediários, como a Meta 1, que estabelece a universalização da educação infantil na pré-escola para a população de 4 a 5 anos até 2016; a Meta 7, que define níveis para o Índice de Desenvolvimento da Educação Básica (Ideb) ao final de cada Ciclo de Monitoramento; ou a Meta 20, que determina a ampliação do investimento público em educação pública ao patamar de $7 \%$ do Produto Interno Bruto (PIB) até o $5^{\circ}$ ano de vigência do PNE. Em que constem tais finalidades intermediárias, é fundamental destacar que a maior parte dos objetivos do Plano tem como prazo para sua conclusão o ano de 2024, e isso precisa ser considerado em seu monitoramento ou nas avaliações que são conduzidas acerca de sua eficácia e efetividade. 
Desse modo, nessa etapa não é recomendável buscar respostas definitivas a questões como: “O PNE vai ser cumprido?” O que tem sido feito por meio dos estudos e do monitoramento visa evidenciar as tendências, descrever o quadro atual e trazer informações acerca dos fatores que podem impedir a concretização das metas. Responder à pergunta inicialmente citada só será possível ao final de 2024. Assim, ainda há tempo para elaborar políticas, para mobilizar-se, para reverter tendências e ajustar os rumos da educação.

Cumprida metade da duração doPlano Nacional deEducação, alegra-nos constatar que, a partir do trabalho desenvolvido pelo Inep, o País conta com um eficiente sistema de monitoramento de suas metas educacionais. Entre os seus resultados, queremos destacar que há, efetivamente, avanços fundamentais na educação brasileira: mais de 91\% da população de 4 a 5 anos está na pré-escola; quase a totalidade da população de 6 a 14 anos frequenta ou já concluiu o ensino fundamental; aproximadamente 91,3\% da população de 15 a 17 anos frequenta a escola ou possui a educação básica completa; nos anos iniciais do ensino fundamental, os valores atingidos pelo Ideb são superiores às metas estabelecidas; o percentual de docentes da educação básica com pós-graduação lato sensu ou stricto sensu passou de 31,4\%, em 2014, para 36,2\%, em 2017, entre tantos outros avanços que desafiam o senso comum de que "tudo vai mal na educação". Reconhecer essas conquistas é reconhecer o esforço coletivo dos profissionais da educação que, ainda que enfrentem adversidades, apostam na escola como o local da esperança e da transformação nacional.

Todavia, é preciso reconhecer que os resultados experimentados ainda estão bastante aquém daqueles que desejamos para a educação nacional. Assim, é preciso reafirmar o compromisso com o acompanhamento contínuo das dificuldades nacionais, permitindo o entendimento da realidade educacional em sua complexidade. A feição sintética contida nas metas do PNE precisa levar em conta que ela deriva de esforços, ações, políticas e recursos complexos, de modo que as variações que ocorrem nos indicadores numéricos devem ser tomadas como expressivas de mudanças ou permanências estruturais na educação brasileira.

Esperamos que a experiência que compartilhamos possa ajudar a construir os novos caminhos da educação, assim como desejamos que as reflexões aqui contidas possam ser uma parcela significativa desse esforço. São estudos originados a partir do campo educacional criado pelas metas do PNE, que extrapolam os marcos literais do texto e apontam lacunas, indicam avanços, problematizam os desafios, acenam com novas dimensões para se refletir, analisar e subsidiar o planejamento, gestão, monitoramento e avaliação das políticas educacionais.

Trata-se de um conjunto de evidências educacionais que o Inep entrega à sociedade brasileira. Um esforço coletivo de sua Dired que articulou toda a capacidade técnica reunida no Inep, presente tanto nas pessoas de seus pesquisadores e pesquisadoras como nas tecnologias dos censos educacionais, das estatísticas oficiais, dos exames e das avaliações, construídas no decorrer de sua história, e, por isso, patrimônio do Brasil. 